\title{
AS ESCOLAS NOTURNAS DO MUNICÍPIO DA CORTE: ESTADO IMPERIAL, SOCIEDADE CIVIL E EDUCAÇÃO DO POVO (1870-1889)
}

\author{
AnA LUIZA Jesus dA Costa*
}

\begin{abstract}
RESUMO: Este trabalho expõe parte dos resultados de pesquisa de mestrado desenvolvida sobre as escolas noturnas na Corte. Tem por objeto a ação do Estado imperial na produção dessa experiência de educação do povo. A tese defendida é que o Estado imperial age respondendo à demanda desencadeada por outros atores sociais, como sociedades privadas e a iniciativa individual de professores e alunos. O texto delimita três momentos-chave desta ação estatal: 1854, com a reforma Couto Ferraz; em 1882, as Instruções Provisórias de José Bento da Cunha Figueiredo; e o Decreto n. 7.031, de 6 de setembro de 1878, de Leôncio de Carvalho, quando se instituem os cursos noturnos promovidos pelo Estado. As experiências públicas e privadas de instrução para a população trabalhadora guardam como características comuns a assistematicidade e a precariedade em suas formas.
\end{abstract}

Palavras-chave: Educação do povo. Estado imperial. Município da Corte.

\section{Night schools in Rio de Janeiro's Court: IMPERIAL STATE, CIVIL SOCIETY AND POPULAR EDUCATION} (1860-1889)

ABSTRACT: This work exposes part of a master research results regarding night schools in the Rio de Janeiro's Court. It focuses on the Imperial state action to promote this kind of education. The thesis defended is that the Imperial state acts to respond to a demand made by other social actors, such as private companies and the individual initiative of teachers and students. The text outlines three key-moments in the Court action: The 1854 reform by Couto Ferraz, which only mentions the possibility to instruct illiterate adults; The 1882 Provisional Instructions of José Bento da Cunha Figueiredo, which regulated the private courses that already existed; and the decree $\mathrm{n}^{\mathrm{o}} 7031$ by Leôncio de Carvalho, on September $6^{\text {th }}, 1878$ that established night schools. Public and private experiences to educate the working class share common characteristics: assystematicity and precariousness.

Key words: Popular education. Imperial State. Rio de Janeiro's Court.

\footnotetext{
* Doutoranda em História da Educação pela Faculdade de Educação da Universidade de São Paulo
} (USP). E-mail: anajcosta@usp.br 


\title{
Les écoles nocturnes de la Cour de Rio de Janeiro: ÉTAT IMPÉRIAL, SOCIÉTÉ CIVILE ET ÉDUCATION DU PEUPLE
}

(1870-1889)

\begin{abstract}
RÉSUMÉ: Ce travail expose une partie des résultats d'une recherche de master sur les écoles nocturnes à la Cour de Rio de Janeiro. Son objet est l'action de l'État impérial dans la production de cette expérience d'éducation du peuple. La thèse défendue est que l'État impérial agit pour répondre à une demande provenant d'autres acteurs sociaux, comme des sociétés privées, et de l'initiative individuelle de professeurs et élèves. Le texte délimite trois moments-clé de cette action étatique : 1854, avec la réforme Couto Ferraz ; 1882, avec les Instructions Provisoires de José Bento da Cunha Figueiredo ; et 1878 avec le décret $n^{\circ} 7031$, de Leôncio de Carvalho, qui institue, le 6 septembre, les cours nocturnes promus par l'État. Les expériences publiques et privées d'instruction pour la population ouvrière ont pour caractéristique commune l'asystématicité et la précarité en leurs formes.
\end{abstract}

Mots-clefs: Éducation du peuple. État imperial. Cour de Rio de Janeiro.

$\mathrm{E}$ ducação... quando o senhor chega e diz "educação", vem do seu mundo, o mesmo, um outro. (...) Um estudo que nasce e que vai muito longe dum saberzinho só de alfabeto, uma conta aqui e outra ali. Do seu mundo vem um estudo que muda gente em doutor. É fato? Penso que é, mas eu penso de longe, porque nunca vi isso por aqui. (...).

Mão que foi feita para o cabo da enxada acha caneta muito pesada e quem não teve prazo de um estudozinho regular quando era menino, de velho é que não aprende mais, aprende? Pra quê? Porque eu vou dizer uma coisa pro senhor: pra quem é como esse povo de roça o estudo de escola é de pouca valia, porque o estudo é pouco e não serve pra fazer da gente um melhor. Serve só pra gente seguir sendo como era com um pouquinho de leitura.

Esta fala pertence a um lavrador do Sul de Minas Gerais e foi registrada pelo antropólogo Carlos Rodrigues Brandão, na década de 1980. A entrevista feita com o lavrador Ciço tornou-se prefácio do livro A questão política da educação popular, organizado por Brandão (1980). Este livro parte de uma bibliografia relativamente extensa que procurava compreender as questões a respeito da educação do povo, entendido como parcela da sociedade possuidora de poucos recursos econômicos e políticos e marcada pela necessidade incondicional do trabalho, em suas modalidades mais pesadas e mal remuneradas.

Qual não é a surpresa daquele que passa a se debruçar sobre a história da educação no século xıx: estão lá, quase um século antes de Ciço, Brandão e Freire, os projetos de educação para este mesmo povo, em que pesem as devidas peculiaridades históricas. Debate antigo, antigas respostas. Foi o que encontramos na busca da materialidade e do sentido da experiência educacional das escolas noturnas de instrução primária para adultos existentes no município da Corte, entre 1860 e 1889. Como ponto de partida, adotamos a investigação sobre a ação do Estado - promotor por excelência das políticas educacionais nas sociedades ocidentais modernas. 
Eis que, neste momento, encontramos o mesmo problema levantado por Ciço. Uma política educacional de Estado precarizada, destinada ao trabalhador livre pobre e seus filhos. Sua marca seria a assistematicidade, apesar da existência de legislação relativa à educação de adultos.

Foi possível observar, por meio do mapeamento dos cursos noturnos existentes no período recortado por este trabalho, suas datas de fundação, registros de frequência de estudantes e considerações sobre estes estabelecimentos contidas em relatórios oficiais e na imprensa, que o Estado age aí, respondendo a uma demanda desencadeada por outros atores sociais. Esta afirmativa baseia-se na presença marcante de organizações da sociedade civil, sob a forma de associações de caráter beneficente e filantrópico e da tão exaltada "iniciativa individual". Tal precedência das associações em relação ao Estado não diria respeito à idealização em si das aulas noturnas, mas à efetivação do projeto de forma a torná-las uma prática mais ou menos estabelecida.

Havia certo consenso entre sujeitos envolvidos com os principais debates da esfera pública ${ }^{1}$ sobre a importância e valor dos cursos noturnos e sua missão de levar a "luz da razão" e a "redenção da civilização" ao "povo ignorante", "mergulhado em vícios" e "propenso a crimes e todo tipo de barbárie". Nesse sentido, denominei projeto político-pedagógico elitista a orientação presente, tacitamente, tanto nas escolas noturnas promovidas pelo Estado imperial, como naquelas promovidas pela iniciativa particular (Costa, 2007). Tais instituições não seriam criadas para pôr fim ao analfabetismo, mas para organizar, hierarquicamente, saberes e posições sociais. Na massa dos ditos "degenerados" ou entre as ditas "classes perigosas", havia os que podiam ser regenerados e incorporados, ainda que de forma subalterna, aos valores da civilização. Assim, a instrução "salvava" alguns e fornecia o crivo para repressão de outros. Como pontos constitutivos desse projeto podemos observar: a missão civilizatória; a constituição do Estado imperial; formação do mercado de trabalho livre disciplinado, num momento de progressiva extinção do escravismo; formação para cidadania restrita; controle social para manutenção da ordem.

Também Peres (2002), em seu estudo sobre os cursos noturnos da Biblioteca Pública Pelotense, defende a tese de que tais cursos foram instrumentos de controle social das elites sobre os trabalhadores. A autora aponta três formas de controle e disciplina das classes populares no espaço urbano: a repressão policial, a segregação em asilos e hospitais e a educação aliada ao trabalho. "As aulas da Biblioteca Pública Pelotense, previstas desde o primeiro regulamento de 1875 , foram um dos espaços usados na tentativa de adaptar os homens e meninos das classes populares a um modo de vida e de sociedade considerado 'correto' pela elite" (Peres, op. cit., p. 81).

Hébrard (2001), referindo-se à França entre os séculos XVI e XIX, afirma que as necessidades básicas da vida urbana foram usadas pela Igreja católica para levar 
o povo à escola, onde encontrariam a satisfação destas necessidades e onde seriam catequizados. Depois, agências liberais e filantrópicas utilizariam a mesma via para difundir o catecismo da ordem contra as revoltas e revoluções, visando a paz social, característica da modernidade. No mesmo sentido, Viñao Frago (1999) aponta as pressões em favor da escolarização e alfabetização da classe trabalhadora como fruto de motivações ideológicas conservadoras, frente às ideias socialistas e uma cultura operária em gérmen, e da necessidade de uma mão de obra com certa qualificação elementar.

A partir do momento em que alguns saberes são instituídos como necessários ao convívio em uma sociedade que se modernizava e urbanizava, a leitura e a escrita, as quatro operações matemáticas, o sistema métrico decimal e o sistema de pesos e medidas, além de uma série de normas de condutas higiênicas e morais - uma certa "urbanidade" -, o aprendizado desses mesmos saberes que a escola passava a difundir, por meio do ensino de primeiras letras, passa a ser requisitado, de fato, pela população da Corte. Neste ambiente convivia a busca por escolarização por parte de alguns indivíduos e a rejeição da escola por outros. A obtenção dos saberes escolares era, inclusive, motivo de reivindicações, como no caso - estudado por Silva (2000) - do professor Pretextato dos Passos, homem pardo que, em meados do século XIX, junto com os pais de seus alunos, também pretos e pardos, tenta obter a licença para continuar lecionando a esses meninos.

A escola, definida como meio de propagar estes saberes, torna-se então essencial, embora precária. As altas taxas de analfabetismo acompanharam constantes toda a história da educação no Império. Quase todos os relatórios dos ministros dos Negócios do Império ${ }^{2}$ tinham como abertura a frase "a instrução pública está muito longe das nossas aspirações". Nesse contexto, a existência de uma experiência voltada especificamente para trabalhadores, membros das classes subalternas da sociedade, pode ser vista como um "álibi" de padrões e metas estabelecidos para não serem cumpridos. O Estado não poderia estabelecer certas exigências de níveis de escolaridade, como foi o caso do censo literário criado pela reforma eleitoral de 1881, sem que oferecesse o mínimo de condições para obtenção da instrução primária. $\mathrm{O}$ mínimo de condições não queria dizer uma responsabilização com a efetiva alfabetização da população adulta iletrada. Isto porque quem define a escola como regra, e as regras da escola, é quem a nega a determinadas parcelas da sociedade, no caso desse estudo, à parcela da qual provém a clientela dos cursos noturnos.

Se o infeliz trabalhador não podia, durante o século xIX, e continua a não poder em pleno século xxI, frequentar a escola "tal como deve ser", à luz do dia, havia "espíritos elevados", "amigos da humanidade", para possibilitar que, durante a noite, à luz das lamparinas, esses infelizes, "desafortunados da sorte", pudessem receber a instrução necessária, mesmo que a custa de suas poucas horas de descanso, 
para "se libertarem das trevas da ignorância". ${ }^{3}$ Tal instrução necessária terminava no nível primário ou no máximo em um curso para aprendizado de ofício. Um estudo pouco, que "não muda gente em doutor" (Brandão, 1980).

Assim, a ação dos "beneméritos", dirigentes das associações filantrópicas, era mais evidente que a ação estatal, pelo menos até o decreto número 7.031, de 6 de setembro de 1878, de Leôncio de Carvalho, ministro dos Negócios do Império. Este Decreto, em seu artigo primeiro, estabelecia: "em cada uma das escolas públicas de instrução primária do primeiro grau do município da corte, para o sexo masculino, é criado um curso noturno de ensino elementar para adultos, compreendendo as mesmas matérias que são lecionadas naquelas escolas". ${ }^{4}$

Por que o Estado não tomava para si a responsabilidade pela educação de adultos nas escolas noturnas, tal como se fazia com a escola diurna para meninos e meninas? Se é fato o que temos observado durante as pesquisas, que os cursos noturnos das associações particulares tiveram maior vulto que aqueles promovidos pelo Ministério do Império, não é possível ver entre estes dois agentes uma concorrência. Ao contrário, o Estado procurava incentivar a iniciativa particular e, na maioria das vezes, prestava-lhe subsídios. Foram subsidiados pelo governo imperial importantes cursos "privados", como o da Associação Propagadora da Instrução às Classes Operárias da Lagoa, os do Lycêo de Artes e Officios e da Associação Auxiliadora da Indústria Nacional, que funcionou no prédio da Inspetoria Geral da Instrução.

Ao que nos é dado a ver, teria o Estado recursos para subvencionar à iniciativa particular. Porém, não para estabelecer, de forma sistemática, escolas públicas para adultos. Diante de tal postura política, arriscamos levantar a hipótese de que o lugar da escola noturna não era o lugar de um direito dos trabalhadores pobres e analfabetos, mas o lugar de uma dádiva que deveria ser apreciada e devidamente retribuída por estes. Sobre o curso noturno da Sociedade Propagadora da Instrução às Classes Operárias da Lagôa, Martinez (1997) afirma estarem as ações beneficentes também interessadas em ganhos particulares, como a contrapartida em títulos de nobreza e distinções. Também Peres (2002) aponta que as elites pelotenses, constituídas por sujeitos como: intelectuais, poetas, políticos de renome, prósperos comerciantes, charqueadores, não esperaram a iniciativa dos poderes públicos e se anteciparam na "busca pelo progresso", fundando por conta própria uma Biblioteca Pública e cursos noturnos para adultos. A autora analisa que, porém e para além do discurso progressista, seus principais interesses eram o status e os votos.

As aulas noturnas, como a educação voltada para os trabalhadores, principalmente os considerados adultos, continuavam carentes no que concerne às medidas necessárias para sua formalização. Essa afirmação fica mais clara ao lembrarmos que a obrigatoriedade do ensino, medida que de fato comprometia o Estado com o fornecimento desse serviço, incidia apenas sobre crianças de sete a quatorze anos 
de idade. Por outro lado, a política de recrutamento dos homens livres pobres da Corte para a guarda nacional e para o exército, sem a possibilidade de isenção como a que era dada aos jovens que se preparavam para o ensino superior, dificultava ainda mais seu acesso às escolas noturnas e à escolaridade em geral.

\section{A precedência da iniciativa privada}

Um dos principais vieses de abordagem da educação na história do Brasil do segundo reinado é o que a toma como parte do processo de construção do Estado imperial, levado a frente pelos intelectuais e políticos "saquaremas", representantes da elite cafeeira fluminense (Mattos, 1994). Aderimos aqui a essa forma de interpretação, colocando, entretanto, a questão de que, entre os interesses imediatos das elites representadas pelo Estado imperial, haveria outras necessidades anteriores à instrução, principalmente à instrução popular. Foi no limite entre o que era idealizado e o que era possível ao Estado, em seus diálogos e negociações com outros agentes sociais, que se situou a política de educação para trabalhadores.

A legislação imperial preconizava, no Regulamento de 1854, em seu artigo 71: "Quando uma escola do segundo grau tiver dois professores, serão estes obrigados alternadamente por mês ou por ano, a ensinar matérias de instrução primária duas vezes por semana, nas horas que lhes ficarem livres, ainda que sejam em domingos e dias santos, aos adultos que para esse fim se lhes apresentarem". Mas, apesar de ser fruto de preocupação governamental desde o início da década de 1850, a educação de adultos só se estabeleceria com os cursos das associações privadas, em meados da década de 1860. Seus instituidores, em geral, membros de elites econômicas e intelectuais com aspirações a postos de poder e prestígio na vida política da Corte, atuavam, assim, num espaço deixado pelo Estado. ${ }^{5}$

Mattos (1994), ao apontar a importância da política de instrução pública como instrumento de constituição da classe senhorial, de modo a levar a cabo sua expansão necessária, não deixa, por outro lado, de mostrar que, apesar dos esforços saquaremas na "construção de uma escola governamental, os resultados nem sempre eram animadores". Se a difusão da instrução continuava precária entre aqueles classificados por Mattos como "povo mais ou menos miúdo", a política oficial para esta parcela da população continuava a ser a repressão e o recrutamento para tropa.

Imbuída dos novos ideais difundidos pelas revoluções atlânticas, bem como das ideias de progresso das nações e perfectibilidade dos povos, a opinião pública que se desenvolvia na Corte já pedia uma renovação no tratamento das "questões sociais". É importante lembrar que se trata aqui de um período movimentado por intensas discussões sobre o abolicionismo. Crescia, assim, a tendência à defesa do 
ensino da boa conduta, da boa moral, para formação de cidadãos ordeiros e trabalhadores num contexto de progressiva degradação da instituição escravista.

Nesse sentido, os esforços pela instrução foram realizados com a participação da "sociedade civil", muito exaltada pelo próprio poder público, como podemos ver no relatório do ministro dos Negócios do Império, João Alfredo Corrêa de Oliveira, em 1871:

E não posso deixar de notar com o maior prazer que esta é a tendência do espírito público entre nós. A iniciativa individual desperta pelo concurso de donativos valiosos; a caridade associada promove, protege, dirige a educação dos pobres; cidadãos beneméritos criaram e mantém na Corte, em Pernambuco, na Bahia, no Maranhão e em outras províncias, escolas e estabelecimentos de ensino profissional, multiplicam-se associações de artistas com intuito de beneficência, entre os quais figuram a instrução e as assembléias legislativas provinciais, justiça lhes seja feita, com louvável solicitude, vem aumentando todos os anos as despesas que lhes compete decretar. Em tais condições, aos altos Poderes do Estado incumbe aproveitar e auxiliar tão generoso movimento, dar impulso e direção a tão úteis e nobres esforços, e satisfazer as aspirações e exigências da opinião pública. (Grifos meus)

Junto à constituição do Estado imperial temos a constituição do citado "espírito público", que move "cidadãos beneméritos" nos atos de caridade individual ou associada. É em tais mãos que o Estado imperial colocará a instrução para o "povo mais ou menos miúdo". Aos pobres a instrução não é direito, mas dádiva, devida à caridade.

\section{Regulação do Estado e cursos públicos}

A afirmação da precedência da sociedade civil nas ações de instrução para os pobres não excluía, porém, a existência de regulação do Estado nesse campo. A principal alegação sobre a razão desta conduta mais fiscalizadora que promotora da instrução costuma ser a carência de recursos do poder público. É possível observar que a maioria das críticas e proposições contidas nos relatórios dos ministros do Império converge para a solicitação do aumento de verbas para a instrução primária.

Ao que parece, os eloquentes discursos sobre a necessidade e valor da instrução não encontravam correspondência na política orçamentária do governo imperial. Em seu relatório apresentado à Assembléia Legislativa em 1871, João Alfredo Corrêa considera que, diante de tantas carências vividas pela instrução primária, seria necessário dobrar ou triplicar o orçamento para este grau de ensino, caso contrário os projetos destinados a melhorá-la permaneceriam como letra morta. Entre as necessidades da instrução que reclamavam aumento das verbas estavam a:

(...) de aumentar o número das escolas, pois as nossas são menos da quarta parte das que existem nos países cultos menos favorecidos; de ampliar muito o número de professores e remunerá-los melhor para viverem decentemente com os seus vencimentos, e bem assim, de 
elevar o número e vencimentos dos adjuntos e dos empregados da inspeção geral. Precisamos, finalmente, criar escolas primárias de segundo grau, escolas noturnas, escolas normais e bibliotecas.

Se quisermos acudir já a todas essas necessidades teríamos de despender alguns milhares de contos, principalmente nos primeiros anos; mas sendo isso por agora impossível, fique ao menos bem claro que pouco se poderá fazer com a quantia atualmente orçada (...).

Na análise da atuação estatal, encontramos três momentos-chave em relação aos cursos noturnos. Um primeiro momento não se referia diretamente a eles, mas dizia respeito à instrução primária para adultos em horas livres, no já citado artigo 71 do Regulamento de 1854. Neste, apesar de haver indicação à necessidade da instrução de adultos, não há indicação dos meios para promovê-la, adequados à clientela, à população que realmente dela necessitava: homens pobres, ocupados em trabalhar para seu sustento durante o dia. E a realidade da população pobre e trabalhadora não se fazia só de adultos que buscavam seu sustento durante o dia, mas também de crianças trabalhadoras que complementavam a renda da família e que passaram a freqüentar, ao lado dos adultos, as cadeiras das aulas noturnas das associações existentes.

Quanto a isso, o inspetor geral da Instrução, José Bento da Cunha Figueiredo, e o ministro do Império, João Alfredo Corrêa de Oliveira, opuseram restrições no Ato, aqui considerado um segundo momento-chave de deliberação do Estado imperial sobre os cursos noturnos - As Instruções Provisórias sobre as Escolas Noturnas. Como justificativa para a formulação dessas Instruções Provisórias, Figueiredo alegou o fato dos cursos noturnos, até aquele momento, serem fundados e exercidos arbitrariamente, isentos das disposições do Regulamento de 17 de fevereiro de 1854. Nesse sentido, o inspetor tece as seguintes considerações:

$1^{\underline{o}}$ que o fim especial de tais instituições era prover expressamente a necessidade do ensino a respeito das pessoas adultas, que não podem frequentar as escolas públicas ou particulares.

$2^{\underline{o}}$ que não me parecia conveniente a convivência escolar entre menores de 15 anos e adultos de 20 e mais anos, sendo, aliás, de condições muito diversas.

$3^{\text {o }}$ que as horas das lições não deveriam ser indiferentes, aos meninos e aos seus pais, e que a admissão daqueles nas escolas noturnas contribuía para serem despovoadas as escolas públicas.

$4^{\circ}$ que as leis em vigor não permitem abrir escola ou estabelecimento de instrução primária e secundária sem preceder a certas formalidades, e provas de habilitação que afiancem a moralidade e regime escolar, condições que, sendo comuns aos estabelecimentos públicos e particulares, não tinham sido atendidas na criação de ditas escolas quando me parecia inquestionável que elas devem reclamar direção mais firme e inteligente.

Mas como estava convencido da grande vantagem dos cursos noturnos de adultos, porque fariam aproveitar utilmente muitas horas que seriam perdidas ou empregadas em distrações nocivas, e por outro lado lembrava que eram eles custeados pela filantropia 
dos particulares com professores gratuitos, que não queriam sujeitar-se a todo rigor dos regulamentos, entendi e propus que alguma isenção e franquezas fossem provisoriamente concedidas a tais escolas (...).

Destas considerações resultam os avisos ministeriais dados por João Alfredo Corrêa em seu relatório sobre o ano de 1872. Corrêa elogia as "escolas de adultos que por iniciativa particular se estabeleceram", elogia seus instituidores, mas aponta:

$1^{\circ}$ que não devem ser admitidos nessas escolas meninos menores de 15 anos, para os quais estão abertas as escolas públicas; $2^{\circ}$ que, à vista da natureza e origem de tais escolas, as disposições dos Regulamentos gerais, relativas à inspeção e fiscalização das autoridades, devem ser exercidas nelas de modo que não resultem daí embaraços ao desenvolvimento do precioso elemento da iniciativa particular.

Havia discordâncias estruturais em relação à própria concepção do que deveria ser o curso noturno. Para a inspetoria de instrução tratava-se de atender adultos, maiores de 15 anos, que não possuíssem os conhecimentos básicos, tendo ainda, por fim subjacente, "aproveitar as horas perdidas em distrações nocivas". Nocivos eram, pois, os lazeres das classes populares e as suas "horas de reflexão". Para as associações, o fim subjacente era o mesmo. Entretanto, o público a ser atendido não seria dado pela fase da vida estabelecida como adulta a partir dos 15 anos de idade, mas sim pela marca socioeconômica do trabalho. Note-se que, no período aqui estudado, os sujeitos pertencentes às classes populares deparavam-se muito cedo com a necessidade do trabalho, realidade que se manteve, guardadas as devidas proporções, até os dias de hoje. Dessa forma, atendia-se, nos cursos noturnos particulares e mesmo na escola noturna da Câmara Municipal, "crianças" de 10 anos de idade. Por que deveriam ser diferentes as horas de estudos de pais e filhos, se não eram diferentes as suas horas de trabalho?

A proposição da Inspetoria era afirmadora de uma dupla segregação para a criança trabalhadora: as escolas de meninos estavam fechadas àqueles que não podiam se "dar ao luxo" de substituir o trabalho pelo estudo. Por outro lado, a escola noturna também não os poderia aceitar, pois, de acordo com a formalidade que desconsiderava a realidade, estas seriam reservadas para adultos. Entretanto, as tão prezadas formalidades poderiam ser "relaxadas" quando se tratava da regulação das ações das elites. O que tais avisos deixam transparecer é uma disposição do Estado em regular a ação da iniciativa particular, porém dentro de limites daquilo que pudesse ser conflitante. Ou seja, a Inspetoria de Instrução interviria até o ponto em que pudesse provocar "embaraços" para os instituidores.

Nas Instruções era requisitado de "qualquer instituidor singular ou coletivo, de escolas ou colégios de adultos, com ou sem subvenção do governo", uma exposição sobre qual o local das aulas, o programa de ensino a ser seguido, o horário, o regime disciplinar, os nomes dos professores, os estatutos, em se tratando das 
Associações, a habilitação moral e profissional dos professores. Solicitava-se ainda que os instituidores tivessem um livro de matrículas onde constasse dia de entrada e saída de cada aluno e seu aproveitamento. Deste livro deveriam ser extraídos mapas semestrais a serem remetidos ao delegado de Instrução do distrito em que se situava a escola, além de relatório anual sobre os progressos dos cursos. Estariam os estabelecimentos sujeitos, ainda, a visitas dos respectivos delegados de distrito.

Nos dois últimos artigos, encontram-se as principais intervenções do Estado sobre os cursos noturnos, que até aquela altura funcionavam quase unicamente sob direção particular. $\mathrm{O}$ artigo quinto proíbe de serem admitidos nas escolas noturnas os menores de quinze anos ou os que estivessem ou devessem estar nas escolas públicas primárias. O artigo sexto exigia aos instituidores que cobrassem dos alunos a devida vacinação ou mesmo revacinação.

No momento em que foram estabelecidas as Instruções, havia, na cidade do Rio de Janeiro, cerca de onze cursos noturnos. No entanto, nem todos eram de instrução primária. Para esta, havia o curso do Lycêo de Artes e Officios, em funcionamento desde 1858; do Lycêo Literario Portuguez, desde 1868; da Sociedade Auxiliadora da Indústria Nacional, desde 1870; da Sociedade Propagadora da Instrução às Classes Operárias da Lagoa, desde 1871. Ministrado por iniciativa individual de professores públicos, havia, na freguesia de Paquetá, um curso estabelecido pelo professor Januário dos Santos Sabino; na freguesia de São José, pelo professor Antonio Cândido Rodrigues Carneiro e em Guaratiba, pelo professor Joaquim Antonio da Silva Bastos. Havia ainda dois cursos públicos: o da Câmara Municipal, em São Sebastião, fundado em setembro de 1872, e em São Cristóvão, no edifício da escola pública daquela freguesia, fundado por iniciativa do Ministério do Império, em janeiro de 1872.

Até o terceiro momento, aqui considerado como momento-chave de deliberação do Estado imperial sobre os cursos noturnos, qual seja, o Decreto n. 7.031-A, de 6 de setembro de 1878, mantiveram-se os cursos citados, com o acréscimo de três outros fundados pela Sociedade Promotora da Instrução, na Glória, Engenho Novo e Lagoa. Logo após o Decreto, cresceu substancialmente o número de cursos noturnos públicos, chegando a oito: um na freguesia do Sacramento, um na de São José, dois na de Santa Rita, um na de Nossa Senhora da Glória, dois na do Divino Espírito Santo e um na de Nossa Senhora da Conceição do Engenho Novo.

Se o artigo 71 do Regulamento de 1854 era incipiente para a adoção de uma política sistemática de instrução para trabalhadores e se as Instruções de 1872 tinham caráter apenas de controle da iniciativa particular que se propagava, o Decreto n. 7.031-A de 1878 chamaria para o Estado imperial a responsabilidade de organizar efetivamente esse tipo de instrução. Vale a pena transcrever as palavras de Leôncio de Carvalho, com toda sua carga ideológica: 
Na distribuição do ensino, fôra injusto o Estado, se, atendendo exclusivamente às gerações que despontam, deixasse no olvido aquela que já ocupa um lugar na cena política do país e que conta em seu seio uma numerosa classe completamente deserdada do benefício da instrução. Faz-se mister, portanto, ao lado das escolas destinadas a infância, promover a criação de cursos para o ensino primário dos adultos analfabetos, e esta necessidade assume uma importância particular quando se trata da realização de uma reforma como a do sistema eleitoral, para cujo êxito poderosamente contribuirá o desenvolvimento da instrução popular. Os mencionados cursos nas províncias poderão ser instituídos com pequeno acréscimo de despesa, funcionando, como os ultimamente criados no município da Corte, nos edifícios escolares existentes.

\section{(...)}

No seio dos povos livres nada há tão digno de compaixão como o adulto analfabeto, isto é, o homem que, adiantado na vida física, mas alheio às evoluções da vida moral, está separado da comunhão social pelo negro abismo da ignorância. Sabemos todos que a magna aspiração das sociedades modernas consiste principalmente em alargar, quanto possível, o círculo dos seus associados, pela igualdade no exercício dos direitos e no cumprimento dos deveres. Como, porém, realizar tão nobre aspiração, sem que a noção desses direitos e deveres haja penetrado mais ou menos profundamente a consciência e a razão de todos?

Como garantir um direito a quem não o sabe exercer e impor uma obrigação a quem não pode cumprir? Foi atendendo a essas considerações que empreendi e levei a efeito a criação dos mencionados cursos. A medida foi realizada com a máxima economia para os cofres públicos, visto que os cursos, como já fiz ver, funcionam nas casas ocupadas pelas escolas públicas, e o ensino é ministrado pelos professores das mesmas escolas, mediante razoável gratificação pelo excesso de trabalho.

A justificativa de Leôncio de Carvalho, bem ao gosto dos discursos liberais, concentra-se na demonstração da "função formativa do cidadão" pelos cursos frente à reforma eleitoral. Esta reforma pretendia adotar a alfabetização como censo, visando restringir o acesso ao pleito a uma minoria privilegiada, num contexto em que graçava o analfabetismo, principalmente entre as classes populares. Ela viria corrigir o fato da renda fixada pela Constituição para determinação dos votantes já estar defasada.

O discurso liberal, sutilmente, faz uma medida de controle de conflitos e manutenção do poder instituído parecer um ato progressista e humanitário. Tudo pelo que lutava era a liberdade dos povos. Contudo, o exercício da liberdade não se poderia efetivar em uma "sociedade ignorante". Confundia-se, assim, desde muito cedo em nossa cultura, instrução e capacidade intelectual. Opunha-se o saber oficial à suposta falta de saber popular, que também implicava incapacidade de discernimento político, enquanto ratificava o lugar da "escola governamental" como única fonte de saber válido. Quem não passasse por ela, não saberia exercer seus direitos, logo, não seria digno deles.

É, porém, em sua ressalva final que ele mostra toda sua contradição interna. Uma medida tão utilitária, humanitária e crucial para a vida política da nação tinha como condição a máxima economia para os cofres públicos. No tempo e no espaço 
e com os recursos que sobrassem, o Estado poderia exercer toda sua compaixão ao adulto analfabeto. Este, por sua vez, deveria lhe ser grato e não reclamar, caso não estivesse habilitado para exercer seus direitos - o voto -, pois lhe fora dada a oportunidade: lá estavam os cursos noturnos de instrução primária para adultos. Os que permanecessem analfabetos o seriam por vontade própria. Afinal, eram livres até para optar entre a "luz da razão" e as "trevas da ignorância".

O fato era que, pela primeira vez, criava-se um decreto específico voltado para a organização de tais cursos na Corte e, logo após esse ato, foram inaugurados mais oito cursos noturnos em escolas públicas: um na freguesia do Sacramento, um na de São José, dois na de Santa Rita, um na Glória, dois na freguesia do Espírito Santo e um na do Engenho Novo.

O texto do decreto contém 48 artigos com prescrições detalhadas sobre o funcionamento dos cursos noturnos, elegendo para isso alguns temas centrais, alvos de maiores preocupações. Estes vão desde a sua implantação, a delimitação do público, os horários, calendário, regime de trabalho e remuneração dos professores, sanções disciplinares, exames e certificados, inspeção, até as despesas do Estado. Cada escola pública do município da Corte para o sexo masculino abrigaria um curso noturno de ensino elementar para adultos, compreendendo as mesmas matérias das escolas diurnas. Os cursos seriam regidos pelos mesmos professores públicos das respectivas escolas, no mesmo período letivo, diariamente, das 17 às 19 horas, de outubro a março, e das 18 às 21 horas de abril a setembro, incluindo os sábados, quando haveria aulas de repetição das matérias lecionadas durante a semana.

Os cursos estavam abertos para matrícula de todas as pessoas do sexo masculino, livres ou libertos, maiores de 14 anos, vacinados e saudáveis. Estavam excluídos da possibilidade da "formação para cidadania" as mulheres trabalhadoras e os escravos, como excluídas estavam da obtenção do "pão espiritual" as crianças trabalhadoras que, por sua condição, não podiam frequentar as escolas públicas diurnas. Para os moradores das freguesias suburbanas havia barreiras adicionais. Enquanto as aulas das escolas urbanas deveriam começar a funcionar imediatamente após o aviso, os das escolas suburbanas deveriam aguardar determinação do Ministério do Império, que examinaria as "condições locais". Entretanto, como medida de cunho liberal, consta a não obrigatoriedade de instrução religiosa para os alunos não católicos e isenção dos exames destas matérias.

Chamam a atenção no decreto as medidas disciplinares e de manutenção da ordem, preocupação central, já que se lidava ali com uma população tida como "desordeira". Os meios disciplinares seriam: primeiro, repreensão em particular; segundo, repreensão em aula; terceiro, eliminação da matrícula e despedida. Havia grande preocupação em prevenir perturbações nas imediações dos edifícios escolares. 
Em casos extremos, o professor poderia contar com o apoio, mesmo nas repreensões dentro de sala de aula, da autoridade policial. Afinal, tratava-se de "classes perigosas". É oportuno citar aqui os artigos referentes à disciplina:

Art. 13. No recinto e nas proximidades da escola os alunos guardarão o maior sossego, respeitando uns aos outros, os funcionários da escola e as pessoas que visitarem o edifício, morarem ou passarem perto dele.

Art. 14. O aluno que sair do recinto da escola sem permissão do professor será pela primeira vez repreendido e nas reincidências se lhe marcará falta.

Art. 15. Os alunos, que dentro da escola perturbarem por qualquer modo os trabalhos, serão pela primeira vez repreendidos e nas reincidências punidos com a nota de mau comportamento.

Art. 16. Os alunos que cometerem graves ofensas à moral e disciplina dentro da escola, fizerem assuadas à porta do estabelecimento, promoverem desordens na rua com seus condiscípulos, ou com os transeuntes ficarão sujeitos à pena de expulsão temporária ou perpétua, imposta pelo professor com recurso para o inspetor geral da Instrução.

Art. 17. O aluno que desobedecer ao professor será mandado retirar da sala, e se não quiser sair, o professor suspenderá a aula, representando ao delegado para que reclame a intervenção da autoridade policial.

Mas não só de repreensão viveram os cursos noturnos do Ministério do Império. Aos bons alunos, que soubessem civilizar seus costumes, aceitando "a luz" ali oferecida, haveria recompensas. Recebendo, os aprovados, título impresso com especificação da nota e assinado por todos os membros da comissão julgadora, teriam o direito de preferência aos lugares de serventes, guardas, contínuos, correios, ajudantes de porteiro, porteiros das repartições e estabelecimentos públicos e outros empregos de igual categoria. Eram atrativos de ascensão social oferecidos pela escola, num momento em que seu principal problema, maior do que o número reduzido de matrículas, era a frequência extremamente reduzida.

Pelo movimento de ofícios trocados entre professores, delegados e inspetoria de instrução, ${ }^{6}$ depositados hoje no Arquivo Geral da Cidade do Rio de Janeiro, é possível entrevermos um pouco das idas e vindas dos cursos noturnos públicos e perceber como esta foi uma política tão instável quanto a frequência de seus alunos. A partir do ano de 1878, o inspetor geral de instrução passou a orientar os delegados de distrito para que se abrissem cursos noturnos assim que se atingissem 12 alunos. Os delegados teriam, então, que empregar "esforços e boa vontade" para aumentar o número de frequentadores dos cursos. Seria necessário sair convidando os analfabetos a desfrutar do "benefício liberalizado pelo governo imperial". Entretanto, em ofício de 10 de novembro de 1879, o governo declarou que, por falta de verbas, deveriam ser fechados os cursos noturnos em funcionamento nas escolas públicas. Vários professores destes cursos enviaram ofícios à Inspetoria Geral de Instrução, propondo-se a continuar as aulas por conta própria. 
Em meados de 1881, os professores que se dispuseram a trabalhar sem receber as devidas gratificações voltaram a solicitar subvenções. Naquele momento, o governo passou a pedir mais informações sobre os cursos antes de conceder as subvenções, ressentindo-se de possíveis fraudes. As subvenções voltaram a ser concedidas por aviso do Ministério do Império de 4 de outubro de 1881, com a ressalva de não se deixar livre ao arbítrio dos professores a abertura dos cursos.

Observa-se, em 1882, um novo movimento de expansão dos cursos públicos. Em 4 de março deste mesmo ano, o inspetor geral de Instrução enviou ofícios para várias freguesias, consultando se seria possível abrir cursos noturnos além dos que já existiam. Todavia, o relatório da Inspetoria geral, de maio de 1882, mostrava-se pessimista em relação aos cursos noturnos. Afirmava não ser nova a ideia de tais cursos, que já existiam muito antes do Decreto n. 7.031-A, de 6 de setembro de 1878 . Dizia que os cursos só teriam sucesso em áreas urbanas e os que prosperaram foram os de associações e sociedades: Imperial Lycêo de Artes e Officios, Sociedade Auxiliadora da Indústria Nacional, Lyceo Literário Portuguez, Sociedade Propagadora da Instrução às Classes Operárias da Lagoa e Associação Promotora da Instrução.

Nos últimos anos do Império, em relatório referente ao ano de 1887, constava a existência de seis cursos noturnos, cuja frequência média foi de 155 alunos. Tendo o relatório sido apresentado no ano de 1887, informava que, de tais cursos, continuava, em 1888, somente o da Sociedade Propagadora da Instrução às Classes Operárias da Lagoa. Conforme o ministro:

Os outros que se achavam estabelecidos nas paróquias do Sacramento, Engenho Novo, Campo Grande e Jacarepaguá, deixaram de funcionar no corrente ano letivo, conforme resolveu meu antecessor a vista da informação da inspetoria geral de instrução pública no sentido de não terem os mesmos cursos apresentado resultados satisfatórios.

E assim, sem mais explicações, foram suprimidos, enquanto nós, que vasculhamos tal história, ficamos sem saber o que significaria, de fato, um curso noturno de instrução primária para adultos ser ou não satisfatório? Satisfatório para quem? Mas não há com o que se surpreender, em se tratando de uma dádiva: como próprio do que é dado, pode ser tirado a qualquer momento. Qual terá sido a reação dos trabalhadores estudantes dos cursos suprimidos? Também os considerariam insatisfatórios? Seu juízo sobre estas questões não consta nos ofícios arquivados.

\section{Notas}

1. Refiro-me aos sujeitos atuantes desde o parlamento até a imprensa, passando pelas participações nas associações particulares para fins públicos. Ao tratar da imprensa, reconhecemos o debate educacional não só em folhas especializadas no assunto, como A Gazeta da Instrução Pública, editada em Niterói e na Corte no ano de 1851, mas também a imprensa ligada às causas abolicionistas e mesmo 
proletárias, como os periódicos O Progresso: órgão dos homens de cor, editado em São Paulo (1899), e A Gazeta Operária: órgão do proletariado do Rio de Janeiro, de 1884, respectivamente.

2. Os "Negócios do Império" eram a pasta responsável pelas políticas educacionais.

3. As expressões usadas entre aspas, podendo parecer ironias, são exatamente os termos adotados na época. A forma mais comum de se referir aos promotores dos cursos noturnos, encontrada nos documentos, era a palavra "benemérito".

4. Anexo ao Relatório do ano de 1877, apresentado pelo ministro e secretário dos Negócios do Império, Dr. Carlos Leôncio de Carvalho, à Assembléia Legislativa em dezembro de 1878. Disponível em: <http://brazil.crl.edu/bsd/bsd/hatness/imperio.html $>$.

5. Esta interpretação pode ser encontrada também no trabalho de Ananias (2000).

6. O códice Ensino Noturno é uma das principais fontes de informação sobre a prática efetiva das aulas noturnas, objeto de análise do presente artigo. Trata-se de uma compilação de documentos relativos ao funcionamento burocrático dos cursos noturnos. São ofícios trocados entre professores, delegados de instrução das freguesias e a Inspetoria de Instrução Primária. Contém, ainda, relatórios, mapas de turma com registros de nome, idade, nacionalidade, endereço e profissão dos estudantes, além de balanços de frequência de alunos.

\section{Referências}

ANANIAS, M. Propostas de educação popular em Campinas: "as aulas noturnas". Cadernos CEDES, Campinas, n. 51, p. 66-77, 2000.

BRANDÃO, C.R. A questão política da educação popular. 4. ed. São Paulo: Brasiliense, 1980.

COSTA, A.L.J. À luz das lamparinas: as escolas noturnas para trabalhadores no município da Corte. 2007. Dissertação (Mestrado em Educação) - Faculdade de Educação, Universidade do Estado do Rio de Janeiro, Rio de Janeiro.

HÉBRARD, J. Por uma bibliografia material das escritas ordinárias: o espaço gráfico do caderno escolar (França, séculos xIx-xx). Revista Brasileira de História da Educação, Campinas, n. 1, p. 115-141, jan./jun. 2001.

MARTINEZ, A.F. Um curso noturno para "operários": a Sociedade Propagadora da Instrução pelas Classes Operárias da Lagoa. In: Martinez, A.F. Educar e instruir: a instrução popular na Corte, 1870 a 1889. 1997. Dissertação (Mestrado) - Instituto de Ciências Humanas e Filosofia, Universidade Federal Fluminense, Niterói.

MATTOS, I.R. A formação do povo. In: MAtTos, I.R. O tempo saquarema: a formação do Estado imperial. 3. ed. Rio de Janeiro: Acess, 1994.

PERES, E. Templos de luz: os cursos noturnos masculinos da Biblioteca Pública Pelotense. Pelotas: Seiva, 2002.

SILVA, A.M.P. Aprender com perfeição e sem coação: uma escola para meninos pretos e pardos na Corte. Brasília, DF: Plano, 2000. 
SILVA, A.M.P. A escola de Pretextato dos Passos e Silva: questões a respeito das práticas de escolarização no mundo escravista. Revista Brasileira de História da Educação, Campinas, n. 4, p. 145-166, jul./dez. 2002.

VIÑAO FRAGO, A. Leer y escribir (siglos XIX-Xx). In: VIÑAo Frago, A. Leer y escribir: historia de dos prácticas culturales. Mexico: IAP, 1999. p. 319-351.

\section{Outras fontes}

CÓDICE Ensino Noturno, no Arquivo Geral da Cidade do Rio de Janeiro, números 4,10 e 11.

GAZETA operária. Órgão proletário do Rio de Janeiro. Rio de Janeiro, v. 1, n. 29, dez. 1884.

O PROGRESSO. Orgão dos Homens de Cor. São Paulo, v. 1, n. 1, 24 ago. 1899.

RELATÓRIOS dos Ministros dos Negócios do Império, entre os anos de 1870 e 1889. Disponível em: <http://brazil.crl.edu/bsd/bsd/hatness/imperio.html>.

Recebido em setembro de 2008.

Aprovado em dezembro de 2008. 